\title{
Madelung's Deformity: Reverse Wedge Osteotomy of the Distal Radius Associate Ulnar Wedge Osteotomy: A Case Report
}

\author{
Kouassi Kouamé Jean Eric, Sery Bada Justin Leopoeld Niaoré, Yao Loukou Blaise, \\ M'bra Kouame Innocent, Krah Koffi Léopold, Kouassi Aya Adelaide Nathacha, \\ Assere Yao Aboh Ganyn Robert Arnaud, Kodo Michel
}

Traumatology and Orthopedics Surgery of the University Hospital of Bouake, Bouake, Cote d'Ivoire

Email: medericko@yahoo.fr

How to cite this paper: Eric, K.K.J., Niaoré, S.B.J.L., Blaise, Y.L., Innocent, M.K., Léopold, K.K., Nathacha, K.A.A., Arnaud, A.Y.A.G.R. and Michel, K. (2018) Madelung's Deformity: Reverse Wedge Osteotomy of the Distal Radius Associate Ulnar Wedge Osteotomy: A Case Report. Open Journal of Orthopedics, 8, 33-38. https://doi.org/10.4236/ojo.2018.82004

Received: December 26, 2017

Accepted: January 30, 2018

Published: February 2, 2018

Copyright $\odot 2018$ by authors and Scientific Research Publishing Inc. This work is licensed under the Creative Commons Attribution International License (CC BY 4.0).

http://creativecommons.org/licenses/by/4.0/

\begin{abstract}
Madelung deformity is rare, accounting for $1.7 \%$ of congenital anomalies. The treatment is essentially surgical and several techniques have been described. We report the result of a case treated in an adult patient by a double osteotomy of the radius and ulna. The patient is satisfied.
\end{abstract}

\section{Keywords}

Madelung Deformity, Cuneiform Osteotomy, Radius, Ulna

\section{Introduction}

Madelung's deformity was described in 1878 as a "rarely symmetrical, predominantly feminine", spontaneous and progressive "wrist subluxation of the wrist" [1]. It is rare and represents $1.7 \%$ of congenital anomalies [2]. The treatment is surgical and several techniques have been described [3] [4] [5] [6] [7]. The cuneiform osteotomy of distal radius reversal (OCR) associated with an osteotomy subtraction of the ulna gives a good result [1]. We report a severe case in a patient treated by this technique with a good result.

\section{Case Report}

Miss OC 21 years of right laterality, no particular antecedents, consulted 2014 for a double discomfort: an esthetic discomfort by a deformation of the right forearm, and of the right wrist and a discomfort during the practice of the sport and the performing daily tasks due to pain. Symptomatology had been evolving for several years. On clinical examination, there was a posterior projection of the 
ulnar head on the right associated with palmar carpal discharge and curvature of the radius (Figure 1). The patient was clinically evaluated at the level of pain using the Visual Analogue Scale and level is 0 to $10 \mathrm{~cm}$, the gripping force of the Jamar dynamometer in $\mathrm{kg}$ and the articular amplitudes using a goniometer in degrees (Table 1).

The radiography of the forearm and wrist, frontal and profile incidence, revealed the injuries characteristic of the Madelung Deformity (Figure 1). We first performed a wedge-shaped osteotomy of the radius reversal (OCR) [1], then an osteotomy (shortening and subtraction) at six centimeters from the ulnar styloid to remove the persistent ulna-carpal conflict (Figure 2). The amount of ulna to be resected was previously calculated on the preoperative radiographs so as to reduce the ulnar variance to zero. The whole stabilized by two plates in compressions (Figure 3 ). The wrist was immobilized postoperatively with a six-week forearm cast, followed by progressive re-education. The patient was satisfied with the clinically corrected deformity. After a 22-month follow-up we proceeded to remove the osteosynthesis material (Figure 4). This intervention allowed this girl to find an improvement in grip strength, joint mobility of the wrist and pain. The recovery of strength and satisfactory mobility allowed him to resume the sport and daily activities. The aesthetic appearance is satisfactory by disappearance of the projection of the ulnar head and the curvature of the radius as shown by the radiological control and the clinical image made after 22 months (Figure 4).

\section{Discussion}

A number of anatomical changes occur in the Madelung deformity resulting in biomechanical alterations leading to a limitation of movements, a decrease in grip strength, aesthetic discomfort and often pain [8]. The treatment is surgical; several techniques have been described [9]. The cuneiform reversal osteotomy (OCR), which we have used, makes it possible to reorient the radial glenus by modifying as little as possible the overall length of the radius. Its principle is the

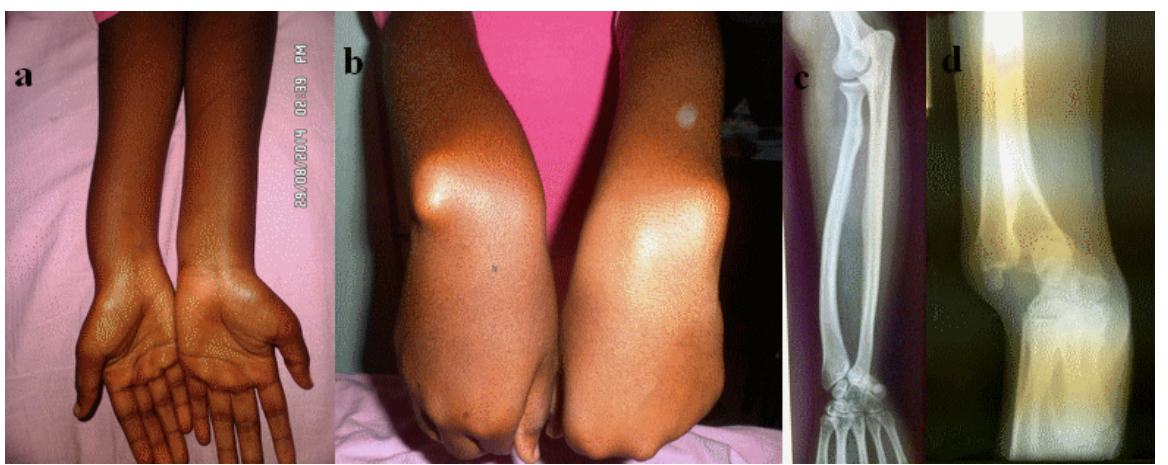

Figure 1. Twenty-one year female patient with left-hand Madelung's deformity. A curvature of the radius and a volar subluxation of the hand, associated with a prominence of the distal end of the ulna (a) (b). An X-ray view of the face and profile of the Madelung Deformity (c) (d). 


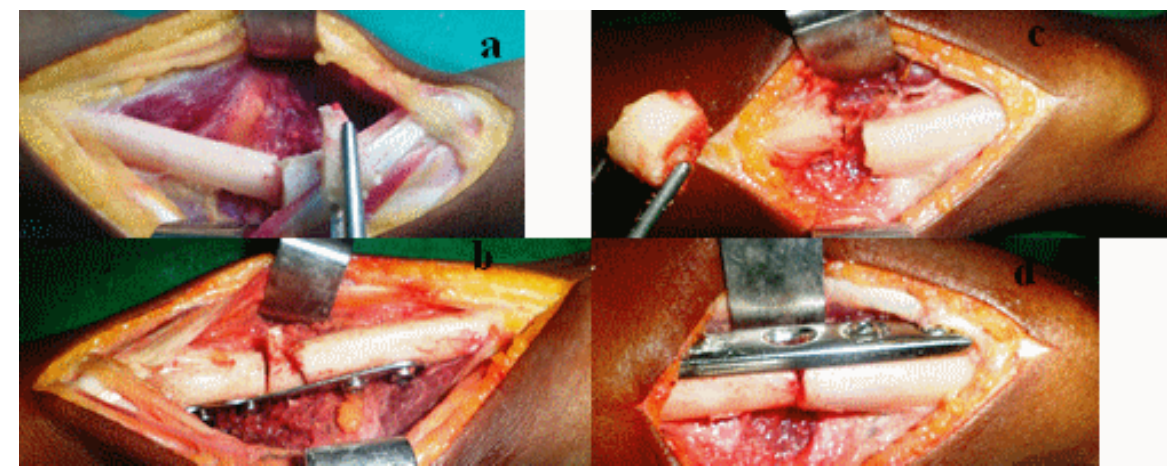

Figure 2. Cuneiform osteotomy of distal radius reversal associated with osteosynthesis by screwed plate (a) (b). Osteotomy of shortening and subtraction of ulna associated with plate osteosynthesis (c) (d).

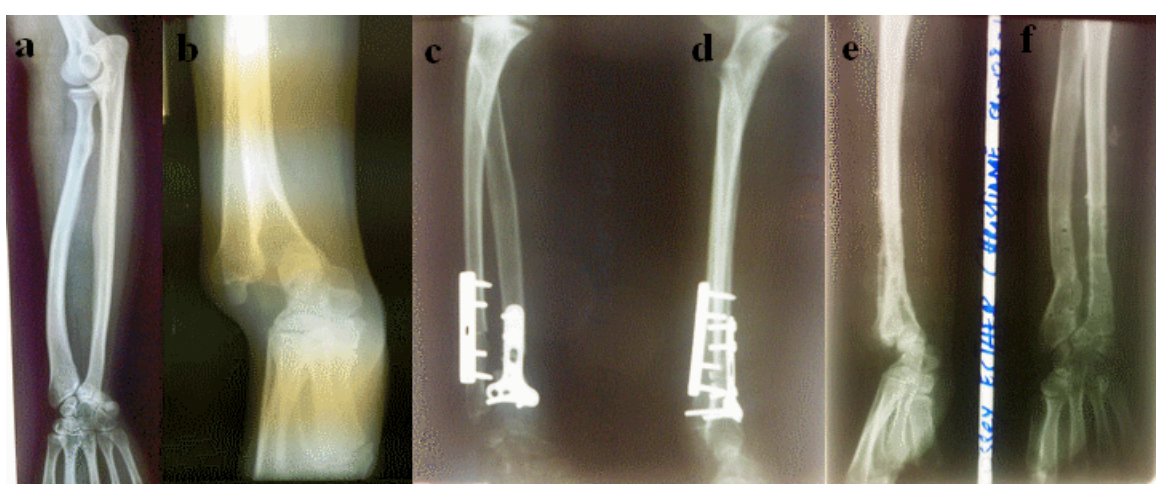

Figure 3. Radiographs showing deformation before surgery (a) (b), postoperative (c) (d) and after removal of the fixation devices at 22 months (e) (f).

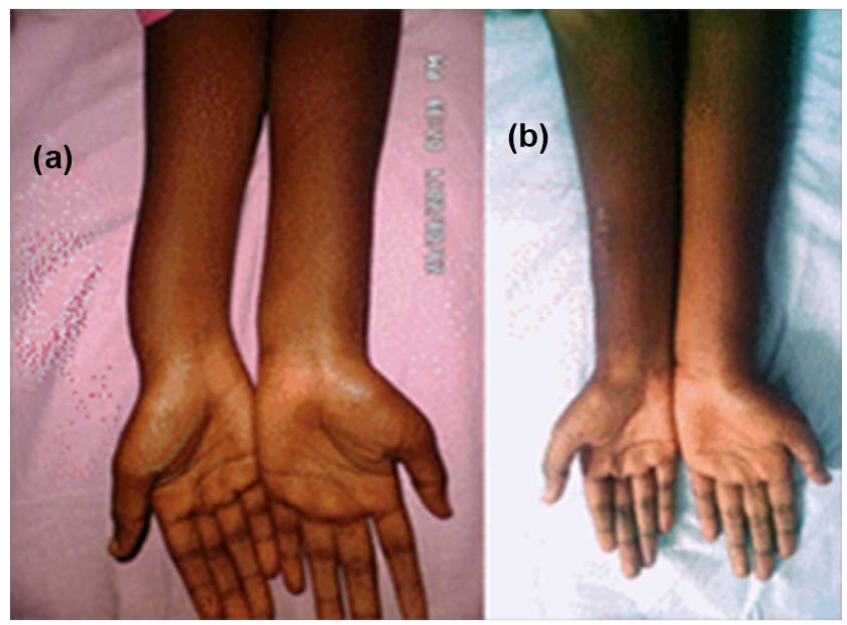

Figure 4. Clinical aspect Preoperative (a) and Postoperative (b).

reversal of a bone wedge taken in situ with a base cut on the excess bone cortices [10]. It associates a subtraction on the surplus cortices and an addition on the deficit corticals which gives it an incomparable power of correction in the three planes of the space [1]. This results in a significant improvement in wrist aesthetics, joint mobility and radiological parameters [1]. 
Table 1. Pre and postoperative ranges of motion of the operated wrist.

\begin{tabular}{ccc}
\hline & Pre operative & Post operative \\
\hline Flexion & $60^{\circ}$ & $75^{\circ}$ \\
Extension & $45^{\circ}$ & $65^{\circ}$ \\
Radial Inclination & $12^{\circ}$ & $17^{\circ}$ \\
Inclinaison cubitale & $25^{\circ}$ & $31^{\circ}$ \\
Pronation & $60^{\circ}$ & $69^{\circ}$ \\
Supination & $45^{\circ}$ & $73^{\circ}$ \\
Gripping force $(\mathrm{Kg})$ & 17 & 28 \\
Pain & 7 & 3 \\
\hline
\end{tabular}

Surgery was performed under general anesthesia with brachial tourniquet. The approach was the lateral face of the radius, to better expose the dorsal and ventral sides of the radius and to protect the sensory branch of the radial nerve as well as the radial artery. The distal end of the radius approached on the dorso-radial slope was largely exposed by the longitudinal incision and then the detachment of the periosteum and the disinsertion of the brachio-radialis tendon. The osteotomy isolated, between two cutting planes on the distal radius, the oscillating saw. The circumferential bone wedge whose base is taken from the excess radial and dorsal cortical bone, leaving the thinnest part of the corner, a thickness of about $1 \mathrm{~mm}$. The bone wedge was then turned over and incorporated into the osteotomy focus to provide a closure on the excess cortices and an opening on the deficit cortices, ensuring perfect contact of the bone section slices to reorient the radial glenoid. Osteosynthesis was provided by a targeted plate, modeled to apply on the ventral cortical while respecting the dorsal discharge of the epiphysis induced by the incorporation of the graft. The plate was fixed by screws on either side of the osteotomy chamber. The shortening osteotomy of the ulna was done by cylindrical subtraction in the diaphyseal zone at the distal third, and then synthesized by a plate with two cortical screws on either side of the osteotomy focus. Watson et al. [3] proposed a technique based on the same principle of combined "open-close" osteotomy. This osteotomy diverges on a fundamental point compared to our technique since the wedge is not circumferential on the whole of the metaphysis, but one half of the epiphysis. The result is a correction in the frontal plane only, since the authors reintroduced the wedge taken from the radial half into the ulnar half of the osteotomy [3]. OCR more proximal than Watson et al osteotomy avoids aggression directly from the distal radioulnar joint and allows the dorsal tilting of the radial epiphysis which will thus join the ulnar head [1]. With regard to addition osteotomy with a free trapezoidal bone graft, described by Murphy et al. in 1996 [6] and modified by de Paula et al. [7] theoretically allows to restore the length of the radius and to reorient the radial glenoid. However, it requires often difficult intraoperative maneuvers and remote engraftment (iliac crest). When the correction is insuffi- 
cient, Murphy et al. perform a second osteotomy of the radius at the diaphyseal level. The elongation of the antebrachial segment is a definite advantage but exposes the risk of dystrophy. Compared to conventional addition osteotomy, OCR is technically easy to perform, without force maneuver, with simple follow-up, probably due to respect of the length of the anti-brachial segment, and does not require bone removal remote [1] [10]. Dos Reis et al. [8] associate with subtraction osteotomy of the radius a shortening of the ulna. This technique gives good results, especially on strength, mobility and appearance of the wrist but aggravates the brevity of the antebrachial segment, which accompanies the deformation of Madelung. Radial closure osteotomies, described in particular by Ranawat, have the disadvantage of shortening the radius, which increases the length difference between radius and ulna, reinforcing the long ulna syndrome [11]. Harley et al. [4] proposed a domed radius osteotomy with Vickers and Nielsen ligament resection. This technique allows to keep the length of the radius and to reorient the radial glenoid in the three planes of space. However, his very intuitive planning seems to us his main limit. Ulnar shortening osteotomy can only be relevant when the dominant clinical picture is that of an ulnar impaction syndrome due to a long ulna associated with an epiphyseal deformity [12] [13], which was the case in our patient. It relieves the pressure in this compartment while tightening the internal structure of the ligament [9]. The OCR associated with a subtraction osteotomy of the ulna seems to us easier technically because without maneuver of force, nor bone removal at a distance and allows significantly improve the patient's daily life. We insist that this technique should be reserved for the severe forms of the Madelung Deformation, for which aesthetic and functional complaints are important.

\section{Conflict of Interest}

The authors state that there is no conflict of interest. The patient was informed and gave contentment for this article.

\section{Author's Contribution}

All the authors contributed to the writing of this manuscript, and had read and approved the final version

\section{References}

[1] Mallard, F., Jeudy, J., Rabarin, F., Raimbeau, G., Fouque, A.P., Cesari, B., et al. (2013) Reverse Wedge Osteotomy of the Distal Radius in Madelung's Deformity. Orthopaedics \& Traumatology: Surgery \& Research: 99S, S279-S283. https://doi.org/10.1016/j.otsr.2013.03.007

[2] Arora, A.S., Chung, K.C. and Otto, W. (2006) Madelung and the Recognition of Madelung's Deformity. Journal of Hand Surgery, 31, 177-182. https://doi.org/10.1016/j.jhsa.2005.09.001

[3] Watson, H.K., Pitts, E.C. and Herber, S. (199) Madelung's Deformity a Surgical Technique. Journal of Hand Surgery, 18, 601-605. 
https://doi.org/10.1016/0266-7681(93)90013-6

[4] Harley, B.J., Brown, C., Cummings, K., Carter, P.R. and Ezaki, M. (2006) Volar Ligament Release and Distal Radius Dome Osteotomy for Correction of Madelung's Deformity. Journal of Hand Surgery, 31, 1499-1506.

https://doi.org/10.1016/j.jhsa.2006.07.012

[5] Vickers, D. and Nielsen, G. (1992) Madelung Deformity: Surgical Prophylaxis (Physiolysis) during the Late Growth Period by Resection of the Dyschondrosteosis Lesion. Journal of Hand Surgery, 17, 401-407.

https://doi.org/10.1016/S0266-7681(05)80262-1

[6] Murphy, M.S., Linscheid, R.L., Dobyns, J.H. and Peterson, H.A. (1996) Radial Opening Wedge Osteotomy in Madelung's Deformity. Journal of Hand Surgery, 21, 1035-1044. https://doi.org/10.1016/S0363-5023(96)80312-1

[7] de Paula, E.J.L., Cho, A.B., Junior, R.M. and Zumiotti, A.V. (2006) Madelung's Deformity: Treatment with Radial Osteotomy and Insertion of a Trapezoidal Wedge. Journal of Hand Surgery, 31, 1206-1213. https://doi.org/10.1016/j.jhsa.2006.06.017

[8] dos Reis, F.B., Katchburian, M.V., Faloppa, F., Albertoni, W.M. and Laredo Filho Jr., J. (1998) Osteotomy of the Radius and Ulna for the Madelung Deformity. The Journal of Bone and Joint Surgery, 80, 817-824.

https://doi.org/10.1302/0301-620X.80B5.8691

[9] Laffosse, J.M., Abid, A., Accadbled, F., et al. (2009) Surgical Correction of Madelung's Deformity by Combined Corrective Radioulnar Osteotomy: 14 Cases with Four-Year Minimum Follow-Up. International Orthopaedics, 33, 1655-1661. https://doi.org/10.1007/s00264-008-0711-Z

[10] Dagrégorio, G. and Saint-Cast, Y. (2005) Reorientation of the Distal Radial Articular Surface in Madelung's Deformity by a Reversed Cuneiform Osteotomy. Hand Surgery, 24, 109-112.

[11] Ranawat, C.S., Ranawat, J. and DeFiore, L.R. (1975) Straub Madelung's Deformity. An End-Result Study of Surgical Treatment. The Journal of Bone and Joint Surgery. American, 57, 772-775.

[12] Aharoni, C., Glard, Y., Launay, F., Gay, A. and Legré, R. (2006) Madelung Deformity: Isolated Ulnar Wedge Osteotomy. Hand Surgery, 25, 309-314.

[13] Bruno, R.J., Blank, J.E., Ruby, L.K., Cassidy, C., Cohen, G. and Bergfield, T.G. (2003) Treatment of Madelung's Deformity in Adults by Ulna Reduction Osteotomy. Journal of Hand Surgery, 28, 421-426. https://doi.org/10.1053/jhsu.2003.50073 